\title{
Autoeducação e liberdade na Pedagogia Waldorf
}

\author{
Jonas Bach Junior \\ Gestor Administrativo-Pedagógico da Associação Sagres, Florianópolis, SC-Brasil. \\ jonasbachjr@yahoo.com.br
}

Tania Stoltz Departamento de Teoria e Fundamentos da Educação da Universidade Federal do Paraná, Curitiba, PR -Brasil. tstoltz@ufpr.br

Marcelo da Veiga Doutor em Filosofia pela Universidade de Duisburg, Alfter - Alemanha. mdv@alanus.edu

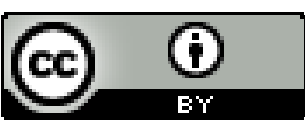

Educação: teoria e prática, Rio Claro, SP, Brasil - elSSN: 1981-8106

Está licenciada sob Licença Creative Common

\section{Resumo}

Este artigo discute o significado de educação para a liberdade na Pedagogia Waldorf. A análise fenomenológica é adotada como suporte para compreensão do autodesenvolvimento da consciência docente em direção à sua potencialidade intuitiva. A autoeducação dos professores é a tradução prática dos fundamentos filosóficos concebidos por Steiner. Na educação Waldorf, a autoeducação é explorada na dialética entre os movimentos psíquicos de simpatia e antipatia em relação ao mundo. A autoeducação seria, então, um princípio do individualismo ético do docente Waldorf para evitar tendências unilaterais do afastar-se ou perder-se da realidade. A conciliação entre os ideais de educação e o contexto real onde educador e educandos se encontram seria realizada pela capacidade criativa, denominada por Steiner de fantasia moral. Para não redundar em prescrições e receitas, ou fórmulas que apenas repetem o passado, o desafio do ideal da Pedagogia Waldorf é uma atualização do professor em nível existencial e profissional.

Palavras-chave: Pedagogia Waldorf. Autoeducação. Liberdade.

\section{Self-education and Freedom in the Waldorf Education}

\section{Abstract}

This paper discusses the meaning of education toward freedom in Waldorf education. The phenomenological analysis is taken as support for self-development of the teacher's 
consciousness toward his intuitive potential. The self-education of teachers is the practical translation of the philosophical foundations elaborated by Steiner. At formation for Waldorf teachers, the self-education is explored in the dialectic between the psychic movements of sympathy and antipathy in relation with the world. The conciliation between the ideals of education and the real context, where teacher and students find themselves, would be achieved through the creative capacity, so-called by Steiner as moral imagination. The selfeducation would then be a principle of ethical individualism of the Waldorf teacher to avoid unilateral tendencies of moving away or losing from reality. To not result in prescriptions or formulas that merely repeat the past, the challenge of the ideal of Waldorf Education is an actualization of the teacher in existential and professional level.

Key words: Waldorf education. Self-education. Freedom.

\section{Introdução}

Dentre os movimentos pedagógicos que surgiram como alternativa à grande formatação que os processos educativos receberam durante sua historicidade, a Pedagogia Waldorf é fundada sobre princípios próprios, que estruturam a singularidade de sua metodologia educacional. Seus fundamentos teóricos, filosóficos e antropológicos, elaborados pelo filósofo austríaco Rudolf Steiner (1861-1925), ampliam a concepção de ser humano e de sua finalidade. São fundamentos focados na questão da liberdade do ser humano.

A liberdade, em Steiner, é essencialmente ontológica, porém, a partir de sua perspectiva fenomenológica-holística, ela também alça parâmetros sociais. Sua educação segue os princípios da fenomenologia do desenvolvimento da consciência, porque, dentro desse desenvolvimento encontra-se o processo para a liberdade do ser humano. Como concepção de liberdade, Steiner apresenta uma especificidade no campo conceitual, desconstruindo noções que incluam o jogo de forças externas (social) e unilateralidades de imperativos racionais (individual) como fatores impeditivos da liberdade. "Se uma decisão racional se impuser igual à fome e à sede, ou seja, sem a minha participação ativa, então só me resta segui-la coagidamente, e a minha liberdade é uma ilusão" (STEINER, 2000, p.19).

A desconstrução do conceito de liberdade de Steiner refuta o atomismo da vontade 'ser livre é aquele que faz o que quer'. A liberdade, em Steiner, refere-se a um processo de autodeterminação da consciência, à atividade pensante. Ela pressupõe um desenvolvimento da consciência que supera os limites apresentados na trivialidade do cotidiano, exige a transcendência de si mesma para alcançar um patamar mais elevado, acima da razão, denominada por Steiner de consciência intuitiva. Esse nível é conquistado através de um 
processo de autoeducação, ou seja, no campo educacional, num primeiro momento, ele é responsabilidade dos educadores.

\section{Da autoeducação à liberdade}

Quando se analisa o papel de certos filósofos na composição de algumas pedagogias, cabe ressaltar que é sempre pelo viés interpretativo de algum pedagogo ou educador que, ao entrar em contato com o universo filosófico, passou a transpô-lo para o campo da educação. As ideias filosóficas, abrangendo o fenômeno da vida como um todo, tornam-se base de inspiração para pensar a educação. As metodologias, propriamente ditas, são estruturadas por especialistas do campo pedagógico. Essa situação não ocorre com a Pedagogia Waldorf. Nela, o sistema filosófico que lhe dá suporte e a estrutura metodológica foram fundamentados pelo próprio Steiner. De tal modo que, entre a teoria e a prática pensadas, não há um filtro de outra personalidade.

Steiner considera o aspecto processual no aperfeiçoamento individual como fator de autoeducação dos professores. A ideia de liberdade não faz sentido, se isolada como discurso teórico. No campo educativo, ela possui duas aplicações a serem verificadas na prática de modo direto: no corpo discente, como seres em formação predominantemente heterônoma, e, no corpo docente, como seres em formação prevalentemente autônoma.

Da estrutura filosófica steineriana à sua composição pedagógica e social, a ponte que conecta campos distintos do saber não é tão evidente. A Pedagogia Waldorf nasceu 25 anos depois d'A Filosofia da Liberdade e ela sequer é citada na autobiografia de Steiner (2006), que teve a narrativa interrompida próximo do ano de 1913, com a morte do autor em 1925. Seus fundamentos filosóficos foram construídos para a humanidade na modernidade. Sua pedagogia foi elaborada depois da incorporação de suas ideias filosóficas numa fundamentação antropológica ampliada, denominada de Antroposofia. ${ }^{1}$

A composição do currículo Waldorf respeita a fenomenologia do desenvolvimento da consciência humana, definindo quais conteúdos são apropriados a certas etapas do

\footnotetext{
1 A aplicação na vida concreta dos fundamentos antroposóficos divide-se em outras áreas do conhecimento como medicina, agricultura, arte, sociedade. No caso da educação, o diretor de uma fábrica - Emil Molt requisitou a adoção desses princípios na formação dos filhos dos operários. A fundação da primeira escola levou o nome da fábrica (Waldorf-Astoria). Na realidade, só há a pedagogia steineriana. Em alguns países Permaneceu o nome da primeira escola Waldorf (Alemanha, Brasil), em outros países, a alusão é direta ao autor (Escola steineriana, pedagogia steineriana).
} 
desenvolvimento humano. Para Steiner, a racionalidade é apenas uma etapa no desenvolvimento da consciência da humanidade. A consciência intuitiva - capaz de apreender a essência das coisas diretamente - é uma etapa posterior, possível somente por conquista do sujeito cognoscente. No campo da educação, a consciência inicia num nível mitológico (primeira infância), passa por estágio ingênuo (segunda infância) e abre-se ao desafio da racionalidade (a partir da adolescência). A metodologia Waldorf vincula-se às orientações gerais sobre como devem se estabelecer os procedimentos pedagógicos de acordo com esses níveis de consciência. $\mathrm{O}$ aspecto relacional envolve a configuração social na realidade de uma escola Waldorf, ou seja, todas as interseções possíveis entre os componentes do organismo social (docentes-discentes, discentes-discentes, docentesdocentes, docentes-familiares...). A fundamentação antropológica abarca o ser humano nas dimensões física, vital, psíquica e espiritual.

A influência schilleriana forneceu proposições fundamentais sobre o poder da mente humana e sua relação com o mundo e centralizou a liberdade como questão principal da evolução espiritual da humanidade. Schiller (1990) discute o problema da fragmentação da mente humana pela cultura moderna. Por um lado, a especialização individual trouxe o benefício ao social, pois permitiu que este alçasse níveis de domínio jamais alcançados na história da humanidade. Por outro lado, o patamar coletivo ascende em detrimento da condição individual. A busca schilleriana é por uma recuperação da potencialidade ampla da mente humana. Para se apreender o todo (o mundo), o ponto de partida deve ser um todo (a mente).

A ponte entre a concepção filosófica da liberdade e sua presença no campo educativo Waldorf depende de um exercício ativo. Steiner fundamenta sua Filosofia da Liberdade nos conceitos de consciência intuitiva, fantasia e técnica moral. A consciência intuitiva é um nível mental acima da racionalidade, que capta a essência dos fenômenos sem ficar restrita aos limites da racionalidade. A fantasia moral é uma capacidade humana de criar representações que orientem o sujeito no seu campo de ação, de acordo com o contexto em que este vive. A consciência intuitiva abrange o universal. A fantasia moral conecta a essência da ideia universal à particularidade do contexto. A técnica moral é o conjunto de conhecimentos em relação ao objeto de ação. Na educação, isto significa um verdadeiro conhecimento do ser humano. 
Schneider (1982) relaciona a consciência intuitiva, a fantasia e a técnica moral com a arte de educar e com a autoeducação dos professores. O pensar intuitivo (consciência intuitiva) dos educadores é a ponte para a apreensão da ideia de educação. O processo educacional é visto como o ensejo para o despertar dessa capacidade latente nos professores. Para que isso ocorra, o educador imbui-se de sua autoeducação. "Naturalmente, a ideia de educação não consiste somente em formar a capacidade de aprender, mas também a de se autorrealizar" (SCHNEIDER, 1982, p.154) ${ }^{2}$. Como fonte de parâmetros, a ideia de educação precisa, sempre, ser reacessada, ela é o norte teórico. Para concretizá-la na realidade, os educadores têm o desafio de ativar sua fantasia moral, sua capacidade de criar representações adequadas ao seu mundo perceptual (contexto). Essas representações visam o direcionamento e a configuração da ação pedagógica, respeitando as leis do desenvolvimento do ser dos educandos (técnica moral).

A autoeducação é considerada como o ativamento de um exercício pessoal para impulsionar a própria capacidade intuitiva e de fantasia do educador, ambas vinculadas com o conhecimento das leis que envolvem o amadurecimento humano. Exercício que pode ser incitado numa perspectiva intrapessoal, ou seja, do profissional que atua com sua individualidade e ideais dentro dessa proposta educativa. O exercício pode explorar a relação interpessoal, investigando como é exercida a ideia de liberdade nos encontros, nas relações sociais, principalmente entre docente e corpo discente.

Também, há na estrutura metodológica a intenção de estabelecer um meio que atuaria como preparo para a liberdade humana. De certa maneira, a ideia de liberdade concebida filosoficamente pressupõe, no mínimo, o homem já amadurecido biologicamente. Assim, quando se reflete sobre a Pedagogia Waldorf, leva-se em consideração que sua aplicação envolve indivíduos em processo de desenvolvimento biológico e psíquico (discentes) e indivíduos que já cumpriram a etapa biológica e encontram-se na evolução anímica e mental.

Se o foco está sobre os discentes, a Pedagogia Waldorf opera com princípios preparatórios para a futura possibilidade da liberdade humana. Nesse sentido, os procedimentos pedagógicos podem ser analisados como exercícios de capacitação e a vida

\footnotetext{
${ }^{2}$ [Selbstverständlich besteht die Idee der Erziehung nicht nur darin, die Lernfähigkeit auszubilden, sondern auch die Selbstverwirklichungsfähigkeit.] (Tradução de Jonas Bach Jr.)
} 
escolar, para crianças e jovens, seria uma vida de treinamento. Assim como uma escola de música não garante que cada aluno se tornará um concertista, mas durante a permanência dos alunos ela oferece experiências que amplificam o desenvolvimento humano para a execução musical, precisa-se olhar a Pedagogia Waldorf com esse enfoque de fase preparatória quando aborda os discentes. A questão de se tornar um concertista, ou de exercer efetivamente a ideia de liberdade na existência concreta, é uma questão de empenho próprio.

A ideia de liberdade é super avançada, mas cada indivíduo parte do estágio onde se encontra. Esse é o princípio do respeito personalizado que rompe com a normatização uniforme da modernidade. Cada indivíduo é realmente compreendido se abordado dentro de suas especificidades. Quantidade de conhecimento adquirido, a profundidade da compreensão, as capacidades conquistadas e habilidades desenvolvidas não possuem um caráter obrigatório. Em vez de ser exigência externa, são alvos para o despertar da vontade própria, para exigência interna. O ideal de liberdade, transposto para a realidade da educação, é traduzido por estímulo a crianças e jovens ao querer interno para o conhecer e o desenvolver-se.

Hoje ninguém deve ser obrigado a compreender. Não exigimos aceitação de quem não sente uma necessidade pessoal para adotar uma determinada convicção. Igualmente não queremos inculcar conhecimentos à criança, mas queremos desenvolver suas faculdades para que ela queira compreender por conta própria e não precise ser obrigada a compreender (STEINER, 2000, p.184)

Verificar esse ideal no âmbito docente é perguntar por uma autoeducação, por uma postura individual preenchida de vontade própria de aprimoramento, amplamente considerado (intra e interpessoal). Rawson (2010) destaca o aprendizado docente sustentável como suporte de sua prática vinculada à teoria. A própria autoeducação é a viabilizadora e confirmadora dos processos pedagógicos conquistados na vinculação entre o contexto docente e a fundamentação teórica. Dentro da concepção filosófica, o ideal de liberdade é questão de uma personalidade. Na realidade pedagógica, tem ponto de partida no indivíduo adulto, mas se torna fato no encontro vivo.

No âmbito educacional, chega-se à ideia de liberdade por vários acessos, o filosófico não é exclusivo. Na própria metodologia, o ideal recebe uma configuração traduzida. $A$ pluralidade de vias de acesso entre a concepção filosófica de liberdade e sua concepção na prática pedagógica torna complexo o seu entendimento, ou, no mínimo, exige mobilidade 
mental para a apreensão em diferentes universos linguísticos. Então, cabe questionar se a expressão filosófica da liberdade adquire propriedade principal, como caminho meditativo ao pensar puro (consciência intuitiva), ou se por outros meios e processos diferenciados desenvolve-se a mesma meta.

Os fatos do cotidiano escolar e tudo que vem ao encontro do professor compõem o universo de suas percepções. Os fatos são os dados com os quais se lida. A ideia de liberdade opera como norte direcionador, ela mantém-se acessível à consciência intuitiva. A realidade nunca se encontra num nível de satisfação, pois cada encontro social é sempre único e não é necessariamente perfeito. A ideia é guia para a transformação de cada fato que está sempre incompleto. A abordagem intelectual, ao projetar o infinito do caráter ideal, que é perfeito em si, para a limitação dos fatos, não encontra o entusiasmo do aperfeiçoamento. A arte do ideal requer um salto da consciência para poder encarar a obstrução com uma vontade inequívoca de transcendência. A pergunta pela verificação do ideal não precisa vincular-se somente ao cunho filosófico, ela pode receber respostas com matizes simplificados.

No extremo oposto da profundidade filosófica, a liberdade é uma pergunta pela sabedoria da vida cotidiana. Questiona-se se o indivíduo que exerce sua existência na Pedagogia Waldorf sabe viver. Ou, por quais meios ele resolve a questão de dar sentido ao seu existir. A ciência se eximiu de responder à questão de qual é o sentido da vida. E no debate acadêmico as tentativas de resposta dividem-se entre niilismos, existencialismos, materialismos, idealismos, criacionismos... Tampouco este estudo é a oferta de uma resposta pronta a quem venha lê-lo. Aliás, não há resposta pronta. Questionar a Pedagogia Waldorf é checar se ela oferece as ferramentas para a construção interna desse sentido. Se não há autoridades externas para a resolução da resposta e se o ambiente cultural pósmoderno é multirreferencial, a postura do individualismo ético está imersa num estado de conflito. Ela é a busca contínua por resolução. O individualismo ético é o exercício de potencializar a conexão do indíviduo com a essência dos fenômenos.

Os exercícios de escala e arpejo constroem a habilidade de um músico. Anos de treinamento contínuo permitem a desenvoltura e a espontaneidade diante de um instrumento. É o preparo que estrutura a expressão livre com o instrumento. Na realidade educativa, esses exercícios correspondem a alguns princípios metológicos. Dentre eles, a prática de ativar na criança a efetivação de conclusões próprias é uma situação de habituar- 
se com a autonomia mental. Isto remete à orientação de Steiner para que os professores não trabalhem com conceitos fechados ou prontos para os alunos.

O hábito de colocar a atividade mental própria dos alunos sob desafios adequados à sua maturidade é o estímulo para a autoconstrução da capacidade pensante. Com o debate em torno do fenômeno atual da infância, a Pedagogia Waldorf tem o desafio de se atualizar frente às mudanças intensas presentes na pós-modernidade (ULLRICH, 2010). Esse processo pedagógico evita que o conteúdo seja meramente expositivo e que a atividade mental discente seja apenas uma imitação do processo conclusivo, já conquistado. Além disso, conclusões prontas podem ser obtidas por diferentes processos. Vivenciar, descobrir ou criar as conclusões próprias é muito mais profícuo para o desenvolvimento das faculdades mentais latentes do que receber passivamente as conclusões prontas. Assim, é na vida escolar que se procura evitar a inclinação humana à unilateralidade mental. A flexibilidade para dominar diferentes processos exige, sempre, mais esforço. O domínio de um processo gera, em seguida, o conforto da passividade. A cultura educativa de expor ao desafio de aquisição de outros processos é o ensejo para ampliar as faculdades mentais.

A dimensão da autoeducação é um dos princípios metodológicos subjacentes ao individualismo ético do professor. Torna-se difícil descrever do que se trata a ideia de liberdade na prática pedagógica se a reflexão envereda por uma evidência perceptível dela. Seria contraditório apresentar os códigos de conduta, seja no plano de ensino e aprendizagem, ou no plano de relações sociais. O receituário e os exemplos da experiência passada são a cristalização de uma inspiração vinculada a uma circunstância específica no tempo e no espaço, implicando em cada qual possuir sua dinâmica, seu espaço interno para o surgimento de novas capacidades. "Como professor e educador, é ainda necessário ter paciência com a própria autoeducação, com o despertar do que realmente pode germinar e crescer dentro da alma" (STEINER, 2005, p.57).

O cotidiano escolar é permeado por possibilidades para que ocorra algo novo, e a educação, em Steiner, é vista como a arte de conciliar a ideia de ser humano com a circunstância apresentada. A arte de educar é o constante desafio de presentificar a individualidade humana. Individualidade, para Steiner, remete, sempre, ao conceito aristotélico de enteléquia, que significa possuir sua própria finalidade. O presente é fecundo se for criado. A mera repetição do passado não abre espaço para a pedagogia da presença, que, num certo sentido, traduz sua referência do espiritual na educação. A experiência da 
liberdade é uma experiência de identidade. O eu só pode se identificar no presente, porque ele sempre é. Por isso, a tradução da ideia de liberdade é composta pela ideia de autoeducação.

Já que, neste processo de devir, o ser humano se encontra como educando e ser emancipado (autoeducador, ou seja, autorrealizador com autorreconhecimento) numa relação de troca com a natureza, com seu próximo, bem como com o ambiente espiritual completo, ele se vê sempre numa trama de desenvolvimento determinada pela polarização da individuação e universalização, na qual respectivamente - pois ambos os pólos formam uma unidade - um dos dois pólos é dominante de acordo com a situação de desenvolvimento (SCHNEIDER, 1982, p.160). ${ }^{3}$

Ensinar, na Pedagogia Waldorf, tem por orientação a busca individual por uma identidade sempre em construção no ato pedagógico. Esse ideal não encontra comparação em qualquer entendimento que espera por uma formatação ou padronização da ação pedagógica. Schieren (2010) discute o problema das percepções fixas como elemento inadequado aos propósitos pedagógicos. O objetivo para os docentes seria trabalhar de tal modo que, entre conceitos, julgamentos e conclusões, haja um movimento flexível. Assim, a autenticidade da Pedagogia Waldorf está imediatamente relacionada com a individualidade que aprende a ensinar. Ambos estão num eterno começo quando se efetivam no aqui e agora do contexto escolar.

Não existe individualidade que se realize fora das relações sociais. A realização depende da dinâmica interativa. O conteúdo de ensino é previamente preparado como suporte dentro do espectro individual. Sua efetivação no ato pedagógico é tanto mais perfeito quanto mais vivificado pela intensidade interacional. A ênfase sobre a autoeducação deve-se à mútua dependência entre a qualidade da interação interpessoal (docente e alunos) com a qualidade da relação intrapessoal (docente consigo mesmo). A profundidade ontológica dessa inter-relação expressa-se na conscientização dos professores Waldorf de que a educação dos alunos se realiza pelo ser do professor, "a diferença principal atuante no ensino decorre da atitude mental do professor em todo o tempo de sua existência, atitude que ele leva para a aula" (STEINER, 1995, p.26). Ou seja, o momento da sala de aula é apenas uma das facetas. Porém, é a existência toda do professor que ali atua.

3 [Da der Mensch als zu Erziehender und als mündig Gewordener (sich selbst Erziehender, d.h. sich selbst erkennend selbst Verwirklichender) in diesem Werdeprozeb in einem Wechselverhältnis zur Natur und zu seinen Mitmenschen sowie zur gesamten geistigen Umwelt steht, befindet er sich immer in einem durch die Polarität der Individuation und Universalität bestimmten Entwicklungsgeschehen, bei dem jeweils - da beide Pole eine Einheit bilden - einer von beiden je nach der Entwicklungssituation dominant ist.] (Tradução de Jonas Bach Jr.) 
A dinamização autoeducativa docente pressupõe um prévio conhecimento do objeto a ser elaborado, o próprio ser humano. Implícito à ideia de autoeducação está todo o conhecimento antropológico pela perspectiva antroposófica. O preparo para a liberdade inclui o desenvolvimento complexo entre os âmbitos cognitivo, afetivo e volitivo do ser humano. A psique humana na Pedagogia Waldorf é considerada sob essa forma tríplice que envolve o campo mental, das emoções e da vontade. A autoeducação é concretizável por uma postura autocrítica em relação a esses três níveis. A dimensão crítica está reservada ao seu aspecto positivo de acordar para as limitações, como estímulo à transcendência dos impasses individuais ou interacionais (KIERSCH, 2011).

A autocrítica é um olhar para o papel de intérprete criativo sobre a dimensão ontológica, que se desenvolve em seu campo cognitivo; sobre a dimensão afetiva e sociológica, no encontro com o outro; e sobre a dimensão volitiva, no estar dentro do mundo. Ao mesmo tempo, a indicação de Steiner é de que o foco autocrítico principal está sobre o processo, não sobre os resultados. Os produtos da ação pedagógica estão relacionados ao passado, compõem o repertório da experiência. Sob a revisão crítica, são parâmetros válidos para a potencialização da dinâmica processual. Se meramente reproduzidos no presente, os produtos portam apenas a forma do passado, estancando a vibração da ideia que deveria se presentificar.

\footnotetext{
Acima desses dois elementos - a compreensão do morto pelo intelecto e a captação do vivo, do evolvente pela vontade - existe no homem algo que só ele, e nenhum outro ser terrestre, traz em si entre o nascimento e a morte: é o pensar puro, não relacionado com a Natureza exterior, mas com aquele elemento suprasensível situado no próprio homem, que faz dele um ser autônomo, algo transcendente inclusive ao inframorto e ao supravivo. Portanto, se queremos falar em liberdade humana devemos observar esse elemento autônomo do homem, o pensar puro e liberto no qual sempre vive também a vontade (STEINER, 1995, p.44).
}

Como contrabalanço à tendência pretérita, Steiner enfatiza e estimula a aplicação da fantasia na prática pedagógica. A fantasia é o elemento vivificador do ensino, o contraponto venturo necessário para o foco entusiasmador no presente, pois ela é a manifestação da vontade. O ensino com fantasia é um ensino com a presença de força criativa.

A liberdade pressupõe o desenvolvimento integral do homem. O componente volitivo é fator indispensável para o amadurecimento global do ser humano. Por isso, a Pedagogia Waldorf não se reduz a depósito e cobrança de informação. A educação para a 
vontade requer uma compreensão profunda e ampla, de acordo com o conhecimento antroposófico. O movimento corporal, explorado na educação - considerado em toda a sua abrangência - desencadeia, simultaneamente, o desenvolvimento afetivo e mental. A compreensão holística do desenvolvimento humano, da inter-relação e reciprocidade no amadurecimento das três dimensões anímicas (psíquicas), compõe a estrutura do conhecimento antropológico. A ênfase no âmbito volitivo desvia o ensino da abstração pura, o aprendizado recebe um cunho prático e fortalecedor da dimensão interna do ser humano. A realidade, assim, é o palco de uma crítica produtiva, de uma verificação ou comprovação pautada pela construção da experiência própria.

As orientações de Steiner aos professores da primeira escola Waldorf são a principal fonte de embasamento no que diz respeito direto às questões pedagógicas. Elas são compostas por uma série de palestras compiladas a partir de um curso de formação ministrado pelo próprio autor. A concepção filosófica da liberdade não é explícita. A ideia de liberdade é traduzida na concepção antropológica e permeia implicitamente as considerações psicológicas. Os procedimentos em sala de aula são genericamente postulados sob a relação da psique humana com a realidade através do pathos (antipatia e simpatia). Antipatia é a manifestação de afastamento entre realidade e psique; simpatia é a expressão de aproximação entre ambas. Na fonte teórica, a ideia de liberdade aparece sob conceitos filosóficos que buscam o desenvolvimento da consciência intuitiva e da fantasia moral. Quando Steiner iniciou a formação dos primeiros professores Waldorf, ele não utilizou seus conceitos filosóficos. A ideia de liberdade foi traduzida no curso para professores como exercício de autoeducação, como autodeterminação da dinâmica de sua própria psique. Os conceitos filosóficos foram traduzidos pelo próprio Steiner como exercício individual que transcende as unilateralidades de simpatia ou antipatia.

A liberdade é compreendida como exercício existencial e educativo dentro de um equilíbrio dinâmico que evita polarizações. A unilateralidade da antipatia ou simpatia, se exercida nos procedimentos pedagógicos, fere o princípio da liberdade humana que necessita de ambas simultaneamente, pois ela só é possível numa terceira amplitude. De antemão, ela nunca existe de forma preconcebida, daí que sua descrição pormenorizada ou esquematizada seja uma detração de seus pressupostos principiológicos. Essa terceira amplitude, não sendo experiência teórica, nem prática vazia, só pode ser reconhecida pela conquista dentro de um aprimoramento individual (autoeducação) contínuo. 
A descrição cabe onde a liberdade não existe, isto é, nas polarizações anímicas. A antipatia é a dimensão ontológica e psicológica que, isoladamente, representa um afastamento do ser humano da realidade. O conhecimento possível devido ao desligamento da interferência e invasão do mundo no ser. Porém, em sua intensidade, a antipatia é a causa da abstração, da desconexão que leva ao absurdo. Por um lado é fonte de poder, porque significa domínio sobre o mundo ao frear seu aspecto invasivo. Por outro lado, é uma prisão, pois depende de uma carga pretérita que Steiner vincula à herança da metempsicose. A antipatia é uma preponderância, no corpo humano, do sistema nervoso, de um esfriamento e uma cristalização do impulso vital. Por isso, a preocupação de Steiner em evitar a polarização antipática, ela é um poder aprisionador do sujeito cognoscente. A vitalidade é absorvida na perpetuação do velho.

A dimensão antipática é necessária, mas não de modo absoluto. Seu pólo oposto, a simpatia, é mais do que um complemento. A simpatia, unilateralmente considerada, é tão insalubre quanto. Como dimensão ontológica e psicológica, é um embeber-se do mundo, um imiscuir-se nele. Em sua forma absoluta, a simpatia é um perder-se, um diluir-se na realidade, uma abertura sem freios ao fluxo do que ainda quer ser. A simpatia é a ênfase no pólo volitivo. O sentido que Steiner emprega ao campo volitivo é abrangente, inclui a participação transformativa do ser na realidade, mas também é a própria realidade introduzindo-se via sentidos e fazendo-se sangue, músculos e corpo. A simpatia é sempre vontade, um ainda não ou o que ainda vem a ser. É uma corrente que vem do futuro.

Ao descrever o fluxo contrário dessas duas correntes, Rudolf Steiner declara: Vocês
compreendem o enigma da consciência quando entendem que a corrente do
desejo, amor e ódio [simpatia] Ihes vem do futuro e encontra a corrente dos
conceitos, vinda do passado [antipatia], em direção ao futuro. A todo o momento,
vocês vivenciam o embate das duas correntes. Se o momento presente representa
este encontro na alma, vocês podem imaginar que as duas correntes chocam-se;
isto acontece na esfera da alma. A consciência é a colisão das duas correntes
(KÖNIG, 2006, p.148).

Nos procedimentos pedagógicos, a liberdade é traduzida sob um movimento anímico (ou psíquico) que responde a essa dinâmica pendular entre as correntes opostas para explorar a possibilidade de encontro e conflito das correntes complementarmente antagônicas. O entendimento dessa liberdade pressupõe uma concepção de alma que através do choque entre as correntes, torna-se consciente, ilumina-se. É uma liberdade para 
ver a dimensão profunda, eternamente efêmera da instantaneidade. Ao mesmo tempo que o eu funda-se no aqui e agora, exibe o quão longínquo pode estar sua efetividade.

A liberdade na educação é a capacidade de tornar novo o velho, de sentir o entusiasmo de reaprender o que já se conhece como se fosse a primeira vez. É também a capacidade de tornar velho o novo, de permitir o fluxo do ainda não passar a ser um já foi. Nesse sentido, a antipatia na educação é o cansaço, é a fadiga entediante na relação com o conhecimento, quando este representa mera acumulação e reprodução do que já foi elaborado. A simpatia, puramente considerada, é um repertório de experiência sem leitura, é uma abertura escancarada ao vindouro, expondo-se ao aleatório do acaso. O ser que só se embebe do mundo, sem digeri-lo, perde-se nele. A antipatia é para a simpatia o contrabalanço equilibrante, o momento de regurgitar o mundo. Pela via simpática, o futuro não traz a liberdade de mão beijada, o passado tampouco a possui.

\section{Conclusão}

A liberdade precisa ser criada e na educação isso significa uma pedagogia da presença da individualidade. Como projeto, não existe como dado ou especulação, só como presentificação. Em sua possibilidade nos instantes, tem um aspecto fugaz. Em seu princípio ontológico, tem um aspecto eterno. O modo instrumental da razão não consegue apreendêla, em sua certeza de que a liberdade é um mito, evidencia uma crença. Para superar a crença, precisaria enfrentar o risco de vivenciá-la.

A forma que Steiner (2005, p.57) encontrou para expressar a liberdade na educação foi "ensino vivo". Esta é a meta da Pedagogia Waldorf. Permear as relações com o conhecimento através de um processo vitalizador. O desafio das escolas ou professores Waldorf é tornar esse ideal uma realidade em sala de aula. Como preparação para a liberdade na vida adulta, a Pedagogia Waldorf inclui a dimensão simpática nos procedimentos pedagógicos que se traduzem pelas vivências de ritmo. As experiências em ciclos têm o intuito de desenvolver o fator da vontade no ser humano, imprescindível ao individualismo ético para, justamente, não redundar na acomodação de apreender o mundo só com a exclusividade do afastamento cognitivo, mas incluir a aproximação volitiva.

A Pedagogia Waldorf faz sua história ao acumular repertórios de seus processos bem sucedidos. O que foi entendido, em certas circunstâncias, como sucesso de um ensino vivo (o velho tornado novo) corre um risco: o que era novo em outro tempo transforma-se em 
velho hoje. Recorrer a parâmetros do que preteritamente foi ensino vivo é fornecer uma amostra legítima de um determinado tempo e espaço. Porém, não evita tornar cristalizado um exemplo que possui validade relativa. Como diretriz teórica para uma prática vivificada, a Pedagogia Waldorf requisita um permanente começar de novo. Se estiver apoiada demasiadamente numa pseudossegurança do passado, perde a oportunidade de ser criadoramente produtiva no presente, o momento da liberdade pedagógica.

\section{Referências}

KIERSCH, J. Waldorfpädagogik im Gespräch. In: LOEBEL, P.(Hrsg.). Waldorfschule Heute: eine Einführung. Stuttgart: Verlag Freies Geistesleben, 2011.

KÖNIG, K. A alma humana. São Paulo: João de Barro Editora, 2006.

RAWSON, M. P.. Sustainable teacher learning in Waldorf education: a socio-cultural perspective. In: RoSE: Research on Steiner Education, Rudolf Steiner University College (Oslo, Noruega) e Alanus Hochschule (Alfter, Alemanha), vol.1, n.2, p.26-42, dezembro de 2010.

SCHIEREN, J. Conclusion, judgement, concept: the quality of understanding. In: RoSE: Research on Steiner Education, Rudolf Steiner University College (Oslo, Noruega) e Alanus Hochschule (Alfter, Alemanha), vol.1, n.2, p. 5-14, dezembro de 2010.

SCHILLER, F. A educação estética do homem: numa série de cartas. São Paulo: Iluminuras, 1990.

SCHNEIDER, P. Einführung in die Waldorfpädagogik. Stuttgart: Klett-Cotta, 1982.

STEINER, R. A arte da educação I. O estudo geral do homem, uma base para a pedagogia. São Paulo: Antroposófica, 1995.

. A filosofia da liberdade: fundamentos para uma filosofia moderna: resultados com base na observação pensante, segundo método das ciências naturais. São Paulo: Antroposófica, 2000.

A arte de educar baseada na compreensão do ser humano. São Paulo: Federação das Escolas Waldorf no Brasil, 2005. 
Minha vida: a narrativa autobiográfica do fundador da Antroposofia. São Paulo: Antroposófica, 2006.

ULLRICH, H. Das Konzept der Kindheit - ein aktuelles Problemfeld der Waldorfpädagogik. In: Paschen, H. (Hrsg.). Erziehungswissenschaftliche Zugänge zur Waldorfpädagogik.

Wiesbaden: VS Verlag für Sozialwissenschaften, 2010.

Enviado em Março/2012

Aprovado em Fevereiro/2013 